\title{
Cerimônia de posse do NOVO DIRETOR DA FAUUSP
}

Profa. Dra. Suely Vilela

Prof. Dr. Sylvio Barros Sawaya

\section{Começa A NOVA gestão fauUsP}

Discurso da Profa. Dra. Suely Vilela, reitora da USP, na posse do Prof. Dr. Sylvio Barros Sawaya, na função de diretor da Faculdade de Arquitetura e Urbanismo da Universidade de São Paulo, em 30/01/2007.

A Faculdade de Arquitetura e Urbanismo da USP, com quase seis décadas de reconhecimento de seu prestígio e contribuição, realiza, hoje, a cerimônia de posse do professor Sylvio Barros Sawaya como seu diretor, função que já desempenha desde dezembro passado. Cumprimento-o pela conquista e a nova etapa da vida acadêmica.

Estendo meus cumprimentos aos professores Maria Angela Faggin Pereira Leite e Paulo Julio Valentino Bruna. Seus méritos acadêmicos os conduziram à lista tríplice, o que valoriza a escolha do professor Sawaya.

Agradeço ao professor Ricardo Toledo Silva, por sua dedicação à FAU, no cumprimento dos compromissos assumidos para seu mandato, e, em especial, pelo novo cargo, o de secretário adjunto da Secretaria de Saneamento e Energia do atual governo do estado de São Paulo. Nossa Universidade se sente honrada por essa distinção concedida a esse professor.

A FAU tem sido bem-sucedida na formação de profissionais críticos e criativos, os quais, além de destacarem-se no mercado, ocupam cargos de importância no governo.

A FAU se originou da reestruturação do antigo curso de engenheiro-arquiteto da Escola Politécnica e esteve sempre à frente de seu tempo, procurando antecipar as demandas geradas pelas mudanças da configuração social. Assim é que, além do curso de Arquitetura e Urbanismo, oferece, desde o ano passado, o de Design.

Atendendo à multidisciplinaridade exigida, hoje, na formação de recursos humanos empreendedores, esse é um curso de graduação interunidades, mantido em parceria com as escolas Politécnica, Comunicações e Artes e a Faculdade de Economia, Administração e Contabilidade.

Sua pós-graduação, até pouco tempo, única do país a oferecer doutorado em arquitetura e urbanismo, já gerou mais de 1.000 doutores, que militam na área acadêmica, no setor público e na iniciativa privada. Pesquisas interdisciplinares sobre temas diversos, fundamentais para o avanço humano, como design de embarcações, planejamento urbano, modelos tridimensionais, entre outros, vêm sendo desenvolvidos pela unidade. Sua participação nessas questões, por meio da pesquisa, vem sendo reconhecida pela comunidade. 
A esse respeito, quero reforçar o fato que o importante não é apenas gerar novos conhecimentos, mas também transferi-los em benefício da sociedade. Diversas iniciativas mostram a preocupação da FAU em estreitar os laços com a comunidade em geral e com ela contribuir decisivamente.

Cursos de especialização, aperfeiçoamento e difusão para profissionais comprovam sua participação na educação continuada.

Além disso, iniciativa que tem merecido destaque é o trabalho desenvolvido por professores e alunos da FAU junto dos moradores do bairro paulistano do Bom Retiro, com apoio do IPT e da Escola Politécnica. Requalificando o uso do espaço, resgata-se a cidadania dessas pessoas.

$\mathrm{O}$ alto desempenho científico e artístico alcançado pela FAU ao longo dos anos somente foi possível graças ao talento do corpo docente, formado por número expressivo de professores qualificados, de alunos e de funcionários.

É importante, também, salientar o reconhecimento que esta faculdade tem merecido da sociedade em razão de sua importância histórica e artística: dos três edifícios que abriga; dois deles, projetados por Carlos Ekmam e João Batista Vilanova Artigas, foram tombados pelo Condephaat.

Manter o papel fundamental da faculdade no ensino e na pesquisa de arquitetura, urbanismo e design, antevendo as necessidades e os desafios dos próximos anos, constitui a missão de seu novo diretor.

O professor Sawaya possui experiência e capacidade necessárias para vencê-los. Bacharel e doutor em arquitetura, especialista em projetos, há mais de 35 anos tem se dedicado às atividades de ensino, pesquisa e extensão da FAU.

Membro de diversos grupos de trabalho, conselhos e comissões, como a que implantou a USP Leste, também desenvolveu atividades de consultoria e administração em outras instituições e empresas. Além disso, foi professor da PUC de Campinas e da Universidade de Brasília.

Conto com a dedicação do professor Sylvio Sawaya, de sua equipe e do vicediretor, professor Marcelo de Andrade Roméro, na tarefa de prover à FAU as condições necessárias para manter seu pioneirismo e liderança.

De minha parte, o professor Sawaya encontrará pleno apoio. Agradeço ao corpo docente, funcionários e alunos, os quais, com seu empenho, construíram um passado que responde pela excelência do presente e pelo brilhantismo do futuro. Desejo, a todos, sucesso na nova gestão!

Muito obrigada!

Profa. Dra. Suely Vilela 


\section{Atividade no ABano. Antes Que o fogo SE APAgUe}

Sylvio Barros Sawaya: Professor do Departamento de Projeto e professororientador no curso de pós-graduação, eleito diretor da FAUUSP para o período 2007-2010.

Fogo lento, coberto de cinzas, brando, às vezes parecendo apagado, vida resumida, escondida, sossegada, tempo de resistência, sob a cinza o fogo, brasa.

Alguns meninos, estudantes universitários, visitaram o então governador do Estado, eram mais de 60 dias de greve, os estudantes paralisados pela representação estudantil, a conversa amena, a autonomia administrativa conquistada, a construção do prédio da FAU, o ônibus para ir ao país e ao continente.

Um dos meninos, politécnico, lembra que o ano não deveria ser perdido e as aulas deveriam ser repostas. 0 então menino é hoje o governador deste mesmo Estado.

Um, outro, estudante de arquitetura, aproveitara a visita para admirar o solar do café transformado em palácio do governo, hoje é o diretor da Faculdade de Arquitetura e Urbanismo.

A persistência explicativa dessa sincronicidade entre mandato estadual e mandato acadêmico diz respeito ao fogo aceso naqueles dias e que se manteve às vezes escondido, às vezes encoberto, mas contínuo e, como braseiro, mantém o calor e a vivacidade, irrompendo em pontos distintos, mas referido a um mesmo decurso do tempo.

Fogo que, como memória viva, incansável, traz esperança e transforma. Tem origem na terra mesma, não é apenas de um grupo de colegas ou de um tempo específico.

Este país que nos acolhe e nos gerou tem a marca de sua terra e de sua gente.

A visão histórica que o explica, hoje, ultrapassou a afirmação apenas simbólica da pátria de há três quartos de século, e é agora acrescida pela interpretação de sua independência como um dos últimos gestos do áncien regime e pelo ferro em brasa que marca sua vida internacionalizada desde então, pela plantation e pela escravatura em suas relações de trabalho. Essas reflexões surgem diante do mundo interdependente e globalizado em que mergulhamos.

Sábias explicações que não esgotam o que somos de fato: uma capacidade incrível de sobreviver, uma procura incansável pela melhora, uma esperança redobrada no futuro, a maioria da população que, mesmo em um contexto altamente elitizado, quer opinar, expressar-se e participar.

Na Faculdade de Arquitetura e Urbanismo isso se reflete pela consideração da relação entre espaço e sociedade. A realização antrópica da vida social é nosso assunto. Tudo o que se faz ocupa um lugar, define um espaço. As grandes redes de comunicação e decisão, sobretudo a econômica, mesmo quase imateriais, têm enormes conseqüências espaciais em suas realizações. Os locais, as imagens e o sentimento de pertencer a um certo canto, assumem importância crescente neste mundo mais e mais conectado. 
A discussão do espaço não é mais apenas a da expansão de sua ocupação, a do crescimento populacional e sua área, é a qualidade desses espaços. E, sobretudo, o encontro com as especificidades de cada espaço e de sua relação com o todo da sociedade.

A sociedade da maioria que apresenta opiniões próprias e desígnios estabelecidos, como o demonstrado no último processo eleitoral, deve ser atingida pela universidade. Esta, por sua vez, não realiza esse movimento de forma plena. Há de trazer-se, portanto, as práticas dessa maioria para a universidade, a fim de serem conhecidas e refletidas e, dessa forma, abrirem campos de indagação e serem passíveis de explicações mais abrangentes. Surge daí a intenção de realizar um Seminário Social da USP na FAU, a todo semestre, de forma a tratar-se um tema fundamental de cada vez, começando pela discussão da habitação social, passando pela manifestação cultural da maioria, indo ao reconhecimento das necessidades das crianças, dos jovens, dos velhos e dos deficientes, passando pela ocupação e desenvolvimento de território considerando a agroindústria, a agricultura de exportação e a urbanização como geopolítica. São alguns dos temas pensados.

O cumprimento da determinação da escritura de doação da Vila Penteado, sede inicial da faculdade, reza que uma vez esta transferida para a Cidade Universitária, a Vila Penteado deverá abrigar uma biblioteca pública voltada para a arquitetura, o urbanismo e a engenharia. Permite a criação de um centro público sobre esses assuntos, importante iniciativa para a faculdade, para a universidade e, sobretudo, para a sociedade, quando poderá apresentar ao público toda a sua contribuição à mesma.

A possibilidade concreta de estágios de residência, em áreas de atuação da faculdade, abre a perspectiva de uma inserção profissional efetiva, com um aprendizado voltado para as questões atuais e as respectivas demandas. Dois anos de residência após a graduação permitirão igualmente uma ação profissional junto de organismos voltados para o atendimento social e para a maioria da população. A sociedade, em suas ênfases, constitui-se como o Hospital das Clínicas da faculdade, como já se afirmou uma vez em tempos idos neste Conselho Universitário.

A essas atividades novas corresponde um conjunto de medidas atualizadas, não mais adstritas à extensão e cultura, enquanto vinculação estruturada com a vida social, mas falam do ensino e da pesquisa.

O ensino de graduação poderá ter sua carga horária condensada a um número de horas equivalente a de um profissional de outras escolas, como, por exemplo, a Politécnica. Isso permitirá que o curso se realize em um turno contínuo de seis horas, restando outro período para estágios, iniciação científica, trabalhos e outros aprimoramentos. A maior interconexão entre os departamentos e a interdisciplinaridade permitirá a atualização dos conteúdos e sua maior ligação com a demanda profissional de fato. A informatização das atividades de ensino possibilitará ganhos de tempo, apresentando mais qualidade e contemporaneidade em relação ao profissional de ponta.

A pós-graduação, tendo seu único programa subdividido em três ou mais programas, permitirá um aprofundamento de assuntos hoje centrais nos campos da arquitetura e urbanismo e a formação de atividades institucionais de pesquisa com caráter temático definido e estrutural. 
A pesquisa marcada por esses grandes tópicos poderá gerar uma atuação acadêmica conseqüente e alçar a um profícuo intercâmbio internacional, desenvolvendo aspectos essenciais para o país e sua gente.

O grande corpo funcional reciclado e remanejado, em função dessas transformações, poderá encontrar novas motivações em seus afazeres, aumentando sua produtividade e rendimento. Será assumido, paralelamente, um esforço para transmitir a todos os objetivos efetivos da instituição em sua dinâmica, acrescido por uma preocupação sincera no incremento e melhora nas atividades de convivência.

Os estudantes de graduação e da pós-graduação, encontrando um ambiente atualizado no tratamento dos assuntos de seu ensino, desenvolverão novamente um sentimento de auto-estima em relação à instituição e obterão, de fato, melhores condições para realizarem suas atividades profissionais e de indagação.

São alguns os tópicos que nestes 45 dias no exercício da direção vieram à tona por uma comunidade aguerrida e sequiosa na procura de futuro mais conseqüente e amplo. Nesse curto espaço de tempo ficou evidente que nossa comunidade se encontra em um ponto importante de mudanças e também de transformação.

Não custa lembrar os outros momentos em que isso já ocorreu. No tempo do professor Anhaia Melo, fundador desta escola, desígnios importantes foram traçados ao se dar à arquitetura e ao urbanismo a autonomia para seu desenvolvimento na universidade. No tempo do professor Vilanova Artigas surge o novo currículo que propõe um arquiteto com sua formação central, una e forte, mas aberto a amplos campos de atuação, construindo-se o novo edifício na Cidade Universitária, a qual se constitui na materialização efetiva dessas perspectivas. No tempo do professor Nestor Goulart a faculdade define sua estrutura acadêmica passando a ser peça importante na formação dos cursos de arquitetura no país, gerando um campo de indagação e de formação válidos na compreensão da área no contexto nacional e internacional.

O novo tempo que se avizinha deverá assumir feição tão importante quanto esses momentos anteriores, mas deverá ser pautado pela ação e participação de todos que compõem nossa comunidade, não se prendendo apenas a uma personalidade exponencial, pois o desafio dessa sociedade internacionalizada, de massa, de consumo e urbanizada em que nos situamos, exige esse esforço comum para ser decifrado e promovido.

A gestão anterior caminhou nesse sentido, ao implantar a dupla formação do arquiteto-engenheiro, ao conquistar a possibilidade de realizar parte do curso em estabelecimento do exterior, ao traçar um plano abrangente e longo de metas e ao instalar, na faculdade, o curso interunidades de Design e Programação Visual; essas iniciativas, bem como outras que começam a ser implementadas, atualmente, têm origem na significativa gestão da professora Maria Ruth Amaral de Sampaio a qual antecede a gestão que ora finda, tendo à frente o professor Ricardo Toledo Silva.

Esse curso, que visa formar quadros essenciais para as atividades produtivas de transformação no país, economizará royalties, trará uma inteligência própria capaz de interpretar nossas especificidades e, a partir deste 
entendimento, participar ativamente das atividades exportadoras. Atenção especial deve ser dedicada a esse curso em formação, instalando laboratórios, vinculando-se a buscas de ponta, e, a partir disso, gerar uma transformação nos velhos hábitos e costumes cristalizados nestas três últimas décadas na veneranda instituição escolar.

Fazer a faculdade estar mais presente, ativamente, nos mapas universitários e de toda a sociedade, trazendo nossa contribuição, afirmando para que servimos e educando pelos instrumentos de ensino e outros, e todos do sentido que a arquitetura tem para a vida pessoal, comunitária e social, parece ser uma boa síntese do que haverá pela frente.

É hora de voltarmos ao chão em brasa que caracteriza a energia e procura desse país. Esse fogo o qual incendiou os corações daqueles meninos há mais de quatro décadas, e que permanece vivo na luta pela transformação e pela melhora da vida de todos, e continua crepitando mais do que nunca. A possibilidade de uma ação mais ordenada em termos do exercício governamental da federação, a perspectiva de uma ação responsável, brilhante e inovadora no Estado, o surgimento das questões regionais e municipais como elementos os mais importantes para a superação de obstáculos, tudo isto tem a ver com a terra e com a gente deste país, com seus lugares, como seus espaços desvendados e a desvendar. Tudo isso fala de um tempo novo para a arquitetura e o urbanismo entre nós.

Não podemos ficar distantes desses debates, devemos participar ativamente por meio do enunciado de novas possibilidades, pela reflexão sobre o que ocorre, pela crítica que aumenta a consciência e a conseqüência na emancipação de todos, em especial, das maiorias que lutam por dias melhores.

Essa perspectiva de grande espectro emula e impulsiona na ação de dirigir, tendo como companheiro de viagem o professor Marcelo Roméro. Entendo ser o papel da universidade a pedra fundamental nesse esforço de versar de forma una, em sua diversidade de conhecimento que é da sociedade, retorna à sociedade e dela retira as luzes para prosseguir.

Um delineamento tão amplo do porvir leva também ao agradecimento de todos aqueles os quais possibilitaram sua existência.

Agradeço a esta universidade por ter à sua frente a energia e o dinamismo de nossa reitora, agradecimento o qual se expande ao rico processo sucessório que pude acompanhar e que, findo, vê a todos irmanados na procura do bem comum.

Agradeço a clareza que iluminou os fundadores dessa casa fazendo-a tão pujante e promissora, agradeço ao ambiente universitário em que nasci, cresci e sempre estive, e o qual me faz acreditar profundamente no espírito universitário e em sua importância, agradeço a todos os que me ensinaram, meus mestres, com quem convivi e convivo.

Há ainda de falar-se do dia de hoje, um dia festivo, de encontro, no qual posso rever a todos vocês, pessoas queridas, e, em conjunto, comemorar um momento de grande felicidade. Nesse sentido agradeço em especial à Soninha e Fernão Bracher os quais, com Brasilinha Arruda Botelho, vão proporcionar-nos com todo carinho um momento de descontração acompanhado de um bom vinho após esta cerimônia.

Prof. Dr. Sylvio Barros Sawaya 